\title{
Effects of $\mathrm{R}$ type and $\mathrm{S}$ type ginsenoside $\mathrm{Rg3}$ on DNA methylation in human hepatocarcinoma cells
}

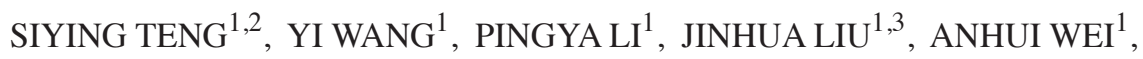 \\ HAOTIAN WANG ${ }^{1}$, XIANGKUN MENG ${ }^{1}$, DI PAN ${ }^{1}$ and XINMIN ZHANG ${ }^{1}$

\begin{abstract}
${ }^{1}$ School of Pharmaceutical Sciences, Jilin University; ${ }^{2}$ Department of Ophthalmology, First Hospital of Jilin University, Changchun, Jilin 130021; ${ }^{3}$ Jilin Entry-Exit Inspection and Quarantine Bureau, Changchun, Jilin 130062, P.R. China
\end{abstract}

Received January 18, 2016; Accepted January 9, 2017

DOI: $10.3892 / \mathrm{mmr} .2017 .6255$

\begin{abstract}
Ginsenoside Rg3, a bioactive constituent isolated from Panax ginseng, exhibits antitumorigenic, antioxidative, antiangiogenic, neuroprotective and other biological activities are associated with the regulation of multiple genes. DNA methylation patterns, particularly those in the promoter region, affect gene expression, and DNA methylation is catalyzed by DNA methylases. However, whether ginsenoside Rg3 affects DNA methylation is unknown. High performance liquid chromatography assay, MspI/HpaII polymerase chain reaction (PCR) and reverse transcription-quantitative PCR were performed to assess DNA methylation. It was demonstrated that 20(S)-ginsenoside $\mathrm{Rg} 3$ treatment resulted in increased inhibition of cell growth, compared with treatment with 20(R)-ginsenoside Rg3 in the human HepG2 hepatocarcinoma cell line. It was additionally revealed that treatment with 20(S)-ginsenoside Rg3 reduced global genomic DNA methylation, altered cystosine methylation of the promoter regions of P53, B cell lymphoma 2 and vascular endothelial growth factor, and downregulated the expression of DNA methyltransferase (DNMT) $3 \mathrm{a}$ and DNMT3b more than treatment with 20(R)-ginsenoside Rg3 in HepG2 cells. These results revealed that the modulation of DNA methylation may be important in the pharmaceutical activities of ginsenoside $\operatorname{Rg} 3$.
\end{abstract}

\section{Introduction}

Ginsenoside $\mathrm{Rg} 3$, which has the chemical name of $12 \beta, 20$ dihydroxydammar-24-en-3 $\beta$-yl2-O- $\beta$-D-glucopyranosyl- $\beta$ D-glucopyranoside, and ginsenoside Rg3 exist in two forms, the $\mathrm{R}$ type and $\mathrm{S}$ type, according to its asymmetric carbon atom (choral carbon atom) C20. Ginsenoside Rg3 has diverse

Correspondence to: Dr Xinmin Zhang, School of Pharmaceutical Sciences, Jilin University, 1266 Fujin Road, Changchun, Jilin 130021, P.R. China

E-mail: zhangxinmin@jlu.edu.cn

Key words: ginsenoside Rg3, DNA methylation, DNA methylases pharmacological effects in vitro and in vivo via the activation or repression of the expression of different genes. Previous studies have reported that ginsenoside $\mathrm{Rg} 3$ inhibits cancer cell proliferation and induces apoptosis by decreasing the expression of histone deacetylase 3 (1), epidermal growth factor receptor (2), fucosyltransferase IV (3) and vascular endothelial growth factor (VEGF) (4), and upregulates the protein expression of pro-apoptotic P53 (1), caspase-3, caspase- 8 and caspase-9 (5). Ginsenoside $\operatorname{Rg} 3$ has been shown to enhance the radiosensitivity of human esophageal carcinoma cells by downregulating the expression of VEGF and hypoxia inducible factor- $1 \alpha(6)$, and ginsenoside $\operatorname{Rg} 3$ may have a neuroprotective function in the rat hippocampus via the inhibition of hippocampus-mediated N-methyl-D-aspartate receptor activation (7). Additional biological activities associated with gene regulation have also been demonstrated for this molecule $(2,8)$.

5-methyl-cytosine (m5Cyt) is the most investigated epigenetic modification, and alterations in genomic DNA methylation patterns have been confirmed to be associated with the development of pathological processes and diseases, including cancer $(9,10)$. It has also been reported that DNA methylation patterns can be altered by medication, nutrients and chemicals (11-13). DNA methyltransferases (DNMTs) are enzymes responsible for establishing the original methylation patterns of de novo methylases, DNMT3a and DNMT3b, and for maintaining these throughout subsequent cellular divisions (maintenance methylase DNMT1). However, until now, there have been no reports on whether ginsenoside Rg3 affects DNA methylation or the expression of methyltransferases.

Global hypomethylation and promoter hypermethylation have been found in hepatocarcinogenesis (14-16); therefore, the present study investigated the effects of ginsenoside $\mathrm{Rg} 3$ on methylation in the HepG2 human hepatocarcinoma cell line. The results showed that ginsenoside Rg3 inhibited HepG2 cell proliferation in a dose-dependent manner, induced a reduction in global DNA methylation, altered methylated cystosines in the promoter regions of specific genes, upregulated the expression of DNMT1, and downregulated the expression of DNMT3a and DNMT 3b. In addition, the different ginsenoside Rg3 epimers exhibited different biological activities. 


\section{Materials and methods}

Reagents. High performance liquid chromatography (HPLC)-grade standards for 20(S)-ginsenoside Rg3 and 20(R)-ginsenoside Rg3 were purchased from Shanghai Yuanye Biotechnology Co., Ltd. (Shanghai, China) and dissolved at a concentration of $50 \mathrm{mg} / \mathrm{ml}$ in dimethyl sulfoxide as a stock solution (stored at $-20^{\circ} \mathrm{C}$ ). This solution was then further diluted in cell culture medium to prepare the working concentrations $(0,7.81,15.63,31.25,62.5,125,250$ and $500 \mu \mathrm{g} / \mathrm{ml})$. 5-methyl-2'-deoxycytidine (5-MedC) was purchased from United States Biological (Salem, MA, USA), and 2'-deoxyguanosine $(\mathrm{dG})$, thymidine $(\mathrm{T}), 2^{\prime}$-deoxycytidine $(\mathrm{dC})$ and 2'-deoxyadenosine (dA) were obtained from Sigma-Aldrich; Merck Millipore (Darmstadt, Germany). Sodium acetate, ammonium formate and acetonitrile were supplied by Beijing Chemical Works (Beijing, China). MNase, nuclease P1 and alkaline phosphatase were purchased from Takara Bio, Inc. (Otsu, Japan).

Analysis of cell viability. Cell proliferation was measured using a Cell Counting Kit-8 (CCK8; Beyotime Institute of Biotechnology, Inc., Jiangsu, China). Briefly, cells of the human hepatocarcinoma cell line HepG2 were cultured in RPMI-1640 supplemented with $10 \%$ fetal bovine serum (Invitrogen; Thermo Fisher Scientific, Inc., Waltham, MA, USA) and $1 \%$ antibiotics-antimycotics in a humidified $5 \% \mathrm{CO}_{2}$ atmosphere at $37^{\circ} \mathrm{C}$. Exponentially growing cells were seeded in a 96 -well plate at a density of $1.0 \times 10^{4}$ cells $/$ well. The following day, the cells were treated in triplicate with the various concentrations of $20(\mathrm{~S})$-ginsenoside $\mathrm{Rg} 3$ or 20(R)-ginsenoside Rg3 for $24 \mathrm{~h}$ at $37^{\circ} \mathrm{C}$. Following incubation for $24 \mathrm{~h}$, cell viability was assessed using the CCK8 assay, according to the manufacturer's protocol. Finally, the absorbance value was recorded at an optical density of $450 \mathrm{~nm}\left(\mathrm{OD}_{450}\right)$ using an enzyme-linked immunosorbent assay plate reader (Emax Plus; Molecular Devices, LLC, Sunnyvale, CA, USA). At least three independent experiments were performed, and the experiments involved three groups: Untreated HepG2 cells (not treated with ginsenoside Rg3), HepG2 cells treated with various concentrations of 20(S)-ginsenoside Rg3 or 20(R)-ginsenoside Rg3 as the experimental group, and a blank group of cell culture only. The inhibition rate was calculated using the following formula: [(untreated group $\mathrm{OD}_{450}$-experimental group $\left.\mathrm{OD}_{450}\right) /\left(\right.$ untreated group $\mathrm{OD}_{450}$-blank group $\left.\left.\mathrm{OD}_{450}\right)\right] \times 100 \%$.

Measurement of global DNA methylation using HPLC. HPLC analysis was performed on a liquid chromatograph coupled with a Waters 2489 UV/visible detector (Waters Corporation, Milford, MA, USA). Separation was achieved on a Symmetry ${ }^{\circledR} \mathrm{C} 18$ (5 $\left.\mu \mathrm{m} ; 4.6 \mathrm{x} 250\right)$ column (Waters Corporation). The mobile phase consisted of solvent A $(50 \mathrm{mM}$ ammonium formate; $\mathrm{pH}$ 5.4) and solvent B (HPLC-grade acetonitrile). The following gradient program used was: Solvent B $2 \%$ at $0 \mathrm{~min}$, solvent B $3 \%$ at $18 \mathrm{~min}$, solvent B $27 \%$ at $25 \mathrm{~min}$, solvent B $35 \%$ at $40 \mathrm{~min}$ and solvent B $2 \%$ at $45 \mathrm{~min}$. The total duration of analysis was $50 \mathrm{~min}$. The flow rate was set at $0.2 \mathrm{ml} / \mathrm{min}$ and the column oven temperature was maintained at $25^{\circ} \mathrm{C}$. UV detection was performed at $277 \mathrm{~nm}$.
The concentrations of MedC and $\mathrm{dC}$ were calculated from linear regression curves, and the percentage of methylation was then calculated using the following equation: $5-\operatorname{MedC}(\%)=[5-\mathrm{MedC} /(\mathrm{dC}+\mathrm{MedC})] \times 100$.

Preparation of standards. The 5-MedC, dC, dA, dT and dG stock standard solutions were prepared by diluting purchased powder in appropriate volumes of HPLC grade water. All stock solutions were then mixed at an appropriate ratio to ensure all components were present at the same concentrations: $0.009765,0.039625,0.156250,0.625000,2.5$ and $10 \mathrm{mM}$ for 5-MedCand dC. All standard solutions were stored at $-20^{\circ} \mathrm{C}$ and used within 1 week.

DNA extraction and hydrolysis. Exponentially growing HepG2 cells were seeded at a density $5.0 \times 10^{5}$ into $75 \mathrm{~cm}^{2}$ culture flasks and, following a $24 \mathrm{~h}$ period, the cells were either left untreated or were treated with 20(S)-ginsenoside $\mathrm{Rg} 3$ or 20(R)-ginsenoside Rg3, in accordance with the cell viability assessment. The cells were then collected, and DNA was purified using a Qiagen DNAeasy ${ }^{\circledR}$ blood and tissue kit (Qiagen GmbH, Hilden, Germany).

Cryonase $^{\mathrm{TM}}$ cold-active nuclease (Takara Bio, Inc.), micrococcal nuclease (Takara Bio, Inc.) and digestion buffer comprising $20 \mathrm{mM}$ Tris- $\mathrm{HCl}, 5 \mathrm{mM} \mathrm{NaCl}$ and $2.5 \mathrm{mM} \mathrm{CaCl}$ (pH 8.0) were added to the purified DNA and incubated at $37^{\circ} \mathrm{C}$ overnight. Alkaline phosphatase (calf intestine; 1 unit/pmol; Takara Bio, Inc.) was added to the samples, and incubation was continued for an additional $4 \mathrm{~h}$. The hydrolyzed DNA was then centrifuged at $18,000 \times \mathrm{g}$ for $20 \mathrm{~min}$ at $4^{\circ} \mathrm{C}$ and adjusted to an appropriate concentration $(\sim 4 \mathrm{mM})$ in HPLC grade water for analysis using HPLC.

MspI/HpaII polymerase chain reaction (PCR) assay. The MspI/HpaII PCR assay was performed as follows: Purified genomic DNA $(2 \mu \mathrm{g})$ from the control and ginsenoside $\mathrm{Rg} 3$-treated samples were digested with 20 units of methylation-sensitive enzymes ( $M s p \mathrm{I}$ or $\mathrm{HpaII}$ ) in a $20-\mu 1$ reaction volume using the buffers supplied by the manufacturer (Takara Bio, Inc.). The reaction mixtures were incubated overnight at $37^{\circ} \mathrm{C}$. The digested DNA samples were purified with phenol:chloroform:isoamyl alcohol (25:24:1) and chloroform extraction, followed by ethanol precipitation.

PCR was performed with the undigested and digested DNA from the control and ginsenoside Rg3-treated samples. A total of 40 primers were designed based on the sequences of the promoter regions of Homo sapiens B cell lymphoma 2 ( $\mathrm{Bcl} 2$; NIH accession no. EU119400; www.ncbi.nlm.nih.gov/nuccore/EU119400), Homo sapiens VEGF gene (NIH accession no. AF095785; www.ncbi.nlm.nih.gov/nuccore/AF095785) and Homo sapiens tumor protein P53 (TP53; NIH accession no. NG_017013; www.ncbi.nlm.nih.gov/nuccore/NG_017013). Each set of primers spanned one or more CCGG sites of the target gene. The primer names, primer sequences and positions of the CCGG sequence for each gene are listed in Table I. Each reaction mixture contained $1 \mu$ l DNA ( 10 ng), $10 \mu 1$ Premix Taq $^{\mathrm{TM}}$ DNA Polymerase Hot-Start (Takara Bio, Inc.),

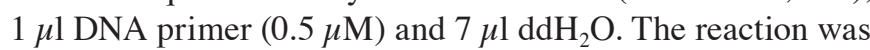
denatured at $95^{\circ} \mathrm{C}$ for $5 \mathrm{~min}$, followed by 40 cycles of $95^{\circ} \mathrm{C}$ 
for $15 \mathrm{sec}, 55^{\circ} \mathrm{C}$ for $45 \mathrm{sec}$ and $72^{\circ} \mathrm{C}$ for $1 \mathrm{~min}$, with a final incubation step at $72^{\circ} \mathrm{C}$ for $5 \mathrm{~min}$. Following agarose gel electrophoretic separation and staining with ethidium bromide, the amplified products were visualized under UV irradiation. Images were captured for further analysis.

Reverse transcription-quantitative PCR (RT-qPCR) analysis. Total RNA was isolated from the cultured cells using the RNeasy ${ }^{\circledR}$ Mini kit (Qiagen $\mathrm{GmbH}$ ) according to the manufacturer's protocol. cDNA was synthesized using a ReverTrace qPCR RT kit (Toyobo Co., Ltd., Osaka, Japan) using an oligo-dT primer, and qPCR was then performed using SYBR ${ }^{\circledR}$-Green Realtime PCR Master mix (Toyobo Co., Ltd.) with forward and reverse primers for each gene. The sequences of the qPCR primers are listed in Table I. To avoid DNA contamination, at least one primer in each set spanned two exons. Each qPCR reaction mixture contained $1 \mu 1$ cDNA, $10 \mu 1$ SYBR $^{\circledR}$ Green Real-Time PCR Master Mix (Toyobo Co., Ltd.), $1 \mu$ l DNA primer $(0.5 \mu \mathrm{M})$ and $7 \mu \mathrm{ldd} \mathrm{H}_{2} \mathrm{O}$. The PCR was performed in a StepOnePlus ${ }^{\mathrm{TM}}$ (Applied Biosystems; Thermo Fisher Scientific, Inc.) with the following thermal cycling protocol: $95^{\circ} \mathrm{C}$ for $5 \mathrm{~min}$, followed by 40 cycles at $95^{\circ} \mathrm{C}$ for $15 \mathrm{sec}$ and then at $60^{\circ} \mathrm{C}$ for $40 \mathrm{sec}$. The relative expression level of each targeted gene was normalized to the expression of GAPDH calculated using the $2^{-\Delta \Delta \mathrm{Cq}}$ quantification method (17).

Statistical analysis. All data were analyzed using descriptive one-way analysis of variance using the SPSS (version 16.0) software package (SPSS, Inc., Chicago, IL, USA). P<0.05 was considered to indicate a statistically significant difference. All data are presented as the mean \pm standard deviation.

\section{Results}

Antiproliferative effects of 20(S)-ginsenoside Rg3 are more marked, compared with those of 20(R)-ginsenoside Rg3. Ginsenoside Rg3 can exist as either the R type or Stype according to its asymmetric carbon atom (Fig. 1). It has been reported that the antiproliferative effects of the different ginsenoside $\mathrm{Rg} 3$ epimers are cell line-dependent. Wu et al (18) showed that the tumor inhibition rate achieved by 20(R)-ginsenoside Rg3 was significantly higher, compared with that by 20 (S)-ginsenoside Rg3 in hepatoma (H22)-bearing mice. Kim et al (19) found that the antiproliferative effect of 20(S)-ginsenoside Rg3 was higher, compared with that of 20(R)-ginsenoside Rg3 in A549 cells at the same concentration. Park et al (20) reported that 20(S)-ginsenoside $\mathrm{Rg} 3$ reduced human gastric cancer cellular proliferation, whereas 20(R)-ginsenoside $\mathrm{Rg} 3$ had no effect. Cheong et al (21) showed that 20(S)-ginsenoside $\mathrm{Rg} 3$ had higher cytotoxic potency, compared with the 20(R) epimer in HepG2 cells.

The present study confirmed the antiproliferative effects of 20(R)-ginsenoside $\operatorname{Rg} 3$ and 20(S)-ginsenoside $\operatorname{Rg} 3$ on the growth of HepG2 cells using a CCK8 assay, which offers higher sensitivity, compared with an MTT assay. The results (Fig. 2A) showed that treatment of cells with 20(S)-ginsenoside $\mathrm{Rg} 3$ over a concentration range of $15.63-500 \mu \mathrm{g} / \mathrm{ml}$ resulted in the inhibition of cellular proliferation, and the antiproliferative effect of 20(R)-ginsenoside Rg3 was observed over a concentration range of $31.25-500 \mu \mathrm{g} / \mathrm{ml}$. Thus, the two epimers inhibited cellular proliferation in a concentration-dependent manner. As shown in Fig. 2B, the linear regression equation for 20(S)-ginsenoside $\mathrm{Rg} 3$ was $\mathrm{Y}=4.1296 \mathrm{X}-5.1012\left(\mathrm{R}^{2}=0.9801\right)$ and the linear regression equation for 20(R)-ginsenoside $\mathrm{Rg} 3$ was $Y=3.2054 X-7.9504\left(R^{2}=0.9714\right)$. From these values, the LD50 of 20(S)-ginsenoside $\operatorname{Rg} 3$ was $178.03 \mu \mathrm{g} / \mathrm{ml}$, whereas that of 20(R)-ginsenoside Rg3 was $326.84 \mu \mathrm{g} / \mathrm{ml}$. Therefore, treatment with $20(\mathrm{~S})$-ginsenoside $\mathrm{Rg} 3$ resulted in more marked inhibition of cell growth, compared with treatment with 20(R)-ginsenoside Rg3. The doses selected for the treatment of cells in the subsequent experiments were $326.84 \mu \mathrm{g} / \mathrm{ml}$

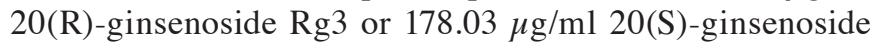
$\operatorname{Rg} 3$.

Ginsenoside Rg3 induces alterations in DNA methylation globally and in the promoter regions of specific genes. The HPLC method used in the present study was modified from that of Fragou et al (22). In the present study, solvent B was changed from methanamide to acetonitrile, as acetonitrile was found to be more effective. From the HPLC chromatogram of standards, it was found that the $\mathrm{C}$ retention time was $\sim 9 \mathrm{~min}$ and the 5-MedC retention time was $\sim 16 \min$ (Fig. 3A). The linear regression equation for $\mathrm{C}$ was $\mathrm{Y}=508781 \mathrm{X}+4356.14$ $\left(\mathrm{R}^{2}=0.99997\right.$; Fig. 3B), and the linear regression equation for MedC was $\mathrm{Y}=190820 \mathrm{X}+782.35\left(\mathrm{R}^{2}=0.99999\right.$; Fig. 3B).

The alterations in DNA methylation in the untreated HepG2 cells and HepG2 cells treated with ginsenoside Rg3 are shown in Fig. 4. The data showed that the average DNA methylation was $3.56 \pm 0.125 \%$ in the untreated cells, $3.36 \pm 0.082 \%$ in the 20(R)-ginsenoside Rg3-treated cells ( $\mathrm{P}=0.115$, vs. untreated group) and $2.66 \pm 0.111 \%$ in $20(\mathrm{~S})$-ginsenoside $\mathrm{Rg} 3$-treated cells $(\mathrm{P}=0.0115)$. The difference between DNA methylation in the 20(R)-ginsenoside Rg3 and 20(S)-ginsenoside Rg3 groups was also statistically significant $(\mathrm{P}=0.0327)$.

20(R)-ginsenoside $\mathrm{Rg} 3$ is known to induce the global hypermethylation of DNA; therefore, the present study examined whether 20(R)-ginsenoside $\operatorname{Rg} 3$ affected the methylation of the promoter region of a specific gene. Zhou et al (23) showed that ginsenoside Rg3 can inhibit HepG2 cell proliferation by downregulating the expression of VEGF. Yuan et al (24) reported that the protein expression of anti-apoptotic $\mathrm{Bcl} 2$ was downregulated and the protein expression of pro-apoptotic P53 was upregulated by 20(S)-ginsenoside Rg3 in HT-29 colon cancer cells. The present study obtained similar results, which showed that P53 was upregulated, and BCL2 and VEGF were downregulated by treatment of the HepG2 cells with ginsenoside Rg3 (Fig. 5A). Therefore, the present study examined whether the altered gene expression levels were associated with the methylation status of the promoter. The primers used are listed in Table I.

The results of the MspI/HpaII PCR analysis of DNA methylation alterations in BCL2, VEGF and P53 genes induced by ginsenoside $\mathrm{Rg} 3$ treatment are shown in Fig. 5. Alterations in DNA methylation at the CCGG sequence (2371-2374 bp) were identified in the promoter of BCL 2 induced by ginsenoside $\mathrm{Rg} 3$, compared with the untreated control. As shown in Fig. 5B, no significant amplification band was detected in the 20(R)-ginsenoside $\mathrm{Rg} 3$-treated sample digested by HpaII or MspI, or in the 20(S)-ginsenoside Rg3-treated sample digested 
Table I. Primers.

\begin{tabular}{|c|c|c|c|c|}
\hline Primer & Primer sequence $\left(3^{\prime}-5^{\prime}\right)$ & Position (bp) & Gene & NCBI accession no. \\
\hline XZ-82 & cagagtcacctgtcttcacag & $1617-1637$ & BCL2 & EU119400 \\
\hline XZ-83 & tctagccgtgtatgagagtgtg & $1750-1772$ & BCL2 & EU119400 \\
\hline XZ-84 & acacactctcatacacggctag & $1750-1751$ & BCL2 & EU119400 \\
\hline XZ-85 & cgccatgaaaacaagggctg & $1915-1934$ & BCL2 & EU119400 \\
\hline XZ-86 & cagccettgttttcatggcg & $1915-1934$ & BCL2 & EU119400 \\
\hline XZ-87 & gccttctgctcaggcctg & $2060-2077$ & BCL2 & EU119400 \\
\hline XZ-88 & caggcctgagcagaaggc & 2060-2077 & BCL2 & EU119400 \\
\hline XZ-89 & gccegctccgetgcgc & 2154-2169 & BCL2 & EU119400 \\
\hline XZ-90 & gcgcagcggagcgggc & 2154-2169 & BCL2 & EU119400 \\
\hline XZ-91 & gttaaaggcgccgcggcag & $2250-2268$ & BCL2 & EU119400 \\
\hline XZ-94 & gaaccgtgtgacgttacgcac & 2344-2364 & BCL2 & EU119400 \\
\hline XZ-95 & caccttcgctggcagcg & $2528-2544$ & BCL2 & EU119400 \\
\hline XZ-96 & caggaggaggagaaagggtg & $2647-2666$ & BCL2 & EU119400 \\
\hline XZ-97 & ggatgactgctacgaagttctc & $2724-2745$ & BCL2 & EU119400 \\
\hline XZ-98 & gcttctagcgctcggcac & $2828-2845$ & BCL2 & EU119400 \\
\hline XZ-99 & gacggaggcaggaatcctc & 2926-2944 & BCL2 & EU119400 \\
\hline XZ-100 & gaggattcctgectccgtc & 2926-2944 & BCL2 & EU119400 \\
\hline XZ-101 & gcacaggcatgaatctctatccac & 3006-3028 & BCL2 & EU119400 \\
\hline XZ-102 & gtggatagagattcatgcctgtg & $3006-3028$ & BCL2 & EU119400 \\
\hline XZ-103 & gcggcggcagatgaattac & $3109-3127$ & BCL2 & EU119400 \\
\hline XZ-104 & tctcgagctcttgagatctc & $3144-3163$ & BCL2 & EU119400 \\
\hline XZ-105 & gattcccagacttctgcttcac & 3194-3215 & BCL2 & EU119400 \\
\hline XZ-106 & gccagactccacagtgcatac & $1370-1390$ & VEGF & AF095785 \\
\hline XZ-107 & ctgagaacgggaagctgtgtg & $1442-1462$ & VEGF & AF095785 \\
\hline XZ-108 & ccattccetctttagccagag & $1743-1763$ & VEGF & AF095785 \\
\hline XZ-109 & cattcacccagcttccetgtg & $1806-1826$ & VEGF & AF095785 \\
\hline XZ-110 & cactccaggattccaacagatc & $1930-1951$ & VEGF & AF095785 \\
\hline XZ-111 & gagccgttccetctttgctag & 2017-2037 & VEGF & AF095785 \\
\hline XZ-112 & acgtaacctcactttcctgctc & 2053-2074 & VEGF & AF095785 \\
\hline XZ-113 & ccaccaaggttcacagcetg & $2142-2161$ & VEGF & AF095785 \\
\hline XZ-114 & caggcttcactgggcgtc & 2199-2216 & VEGF & AF095785 \\
\hline XZ-115 & agcctcagcccctccacac & $2240-2258$ & VEGF & AF095785 \\
\hline $\mathrm{XZ}-116$ & tgtggaggggctgaggctc & $2241-2259$ & VEGF & AF095785 \\
\hline XZ-117 & gatcctcccegctaccag & $2347-2364$ & VEGF & AF095785 \\
\hline XZ-118 & ctggtagcggggaggatc & $2347-2364$ & VEGF & AF095785 \\
\hline XZ-119 & gaatatcaaattccagcaccgag & $2483-2505$ & VEGF & AF095785 \\
\hline XZ-120 & cggtgctggaatttgatattcattg & $2485-2509$ & VEGF & AF095785 \\
\hline $\mathrm{XZ}-121$ & aagccgtcggeccgattc & $2606-2623$ & VEGF & AF095785 \\
\hline$X Z-162$ & ctccatttcctttgcttcctc & $4908-4928$ & P53 & NG_017013 \\
\hline XZ-163 & ctggcacaaagctggacagtc & 4964-4984 & P53 & NG_017013 \\
\hline XZ-164 & cttctcaaaagtctagagccac & $5058-5079$ & P53 & NG_017013 \\
\hline XZ-165 & gcgtgtcaccgtcgtggaaag & $5141-5161$ & P53 & NG_017013 \\
\hline XZ-166 & tggagctttggggaaccttgag & $5422-5443$ & P53 & NG_017013 \\
\hline XZ-167 & gatgtgcaaagaagtacgctttag & $5449-5472$ & P53 & NG_017013 \\
\hline XZ-168 & ctaaagcgtacttctttgcacatc & $5449-5472$ & P53 & NG_017013 \\
\hline XZ-169 & cagacctcaatgctttgtgcatc & $5510-5532$ & P53 & NG_017013 \\
\hline XZ-170 & tcctagtgaaaactggggctc & $5592-5612$ & P53 & NG_017013 \\
\hline XZ-171 & gttgtgggaccttagcagcttg & $5651-5672$ & P53 & NG_017013 \\
\hline XZ-172 & caagctgctaaggtcccacaac & $5651-5672$ & P53 & NG_017013 \\
\hline XZ-173 & atcgetccaggaaggacaaaggtc & $5678-5701$ & P53 & NG_017013 \\
\hline XZ-174 & gacctttgtcettcetggagcgat & $5678-5701$ & P53 & NG_017013 \\
\hline
\end{tabular}


Table I. Continued.

\begin{tabular}{|c|c|c|c|c|}
\hline Primer & Primer sequence $\left(3^{\prime}-5^{\prime}\right)$ & Position (bp) & Gene & NCBI accession no. \\
\hline $\mathrm{XZ}-175$ & ctggtttagcacttctcacttccac & $5761-5785$ & P53 & NG_017013 \\
\hline $\mathrm{XZ}-176$ & gtggaagtgagaagtgctaaaccag & $5761-5785$ & P53 & NG_017013 \\
\hline $\mathrm{XZ}-177$ & ggcagaaatgtaaatgtggagc & $5853-5874$ & P53 & NG_017013 \\
\hline XZ-48 & acaaagaccaggatgagaag & $333-352$ & DNMT1 & AF180682 \\
\hline XZ-49 & cttctcatctttctcgtctc & $576-595$ & DNMT1 & AF180682 \\
\hline XZ-52 & cagaagcgggcaaagaacag & $659-676$ & DNMT3a & AF331856 \\
\hline XZ53 & cttgcgettgctgatgtagtag & $802-823$ & DNMT3a & AF331856 \\
\hline XZ-56 & cagagtatcaggatgggaag & $965-984$ & DNMT3b & AF331857 \\
\hline XZ-57 & agtttgtctgcagagacctc & $1132-1151$ & DNMT3b & AF331857 \\
\hline XZ-60 & gacctcaactacatggtttac & $175-195$ & GAPDH & M33197 \\
\hline XZ-61 & tgatgggatttccattgatg & $264-283$ & GAPDH & M33197 \\
\hline XZ-62 & aggtgcatgtttgtgcetgtc & $875-895$ & P53 & AB082923 \\
\hline XZ-63 & tcttgcggagattctcttcctc & 916-937 & P53 & AB082923 \\
\hline XZ-64 & gctgggatgcctttgtggaac & 2039-2059 & BCL2 & M13994 \\
\hline XZ-65 & tgagcagagtcttcagagacag & $2102-2122$ & BCL2 & M13994 \\
\hline XZ-66 & ccaacatcaccatgcagattatg & 315-337 & VEGF & AY047581 \\
\hline XZ-67 & Tgctgtaggaagctcatctctc & $369-390$ & VEGF & AY047581 \\
\hline
\end{tabular}

BCL2, B cell lymphoma 2, VEGF, vascular endothelial growth factor; DNMT, DNA methyltransferase.

A

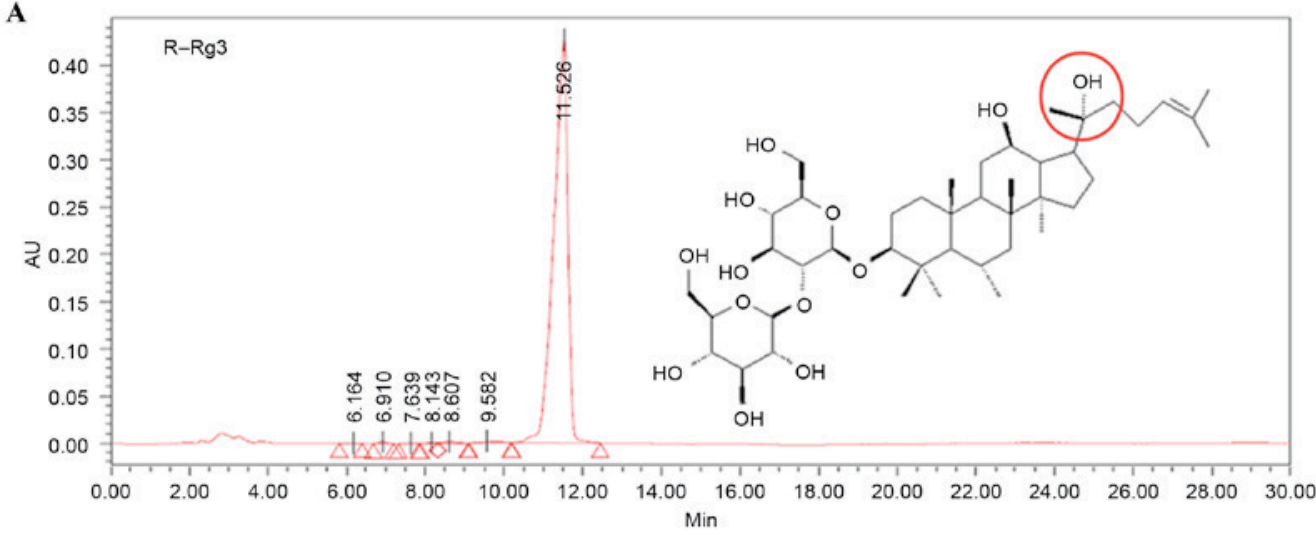

B

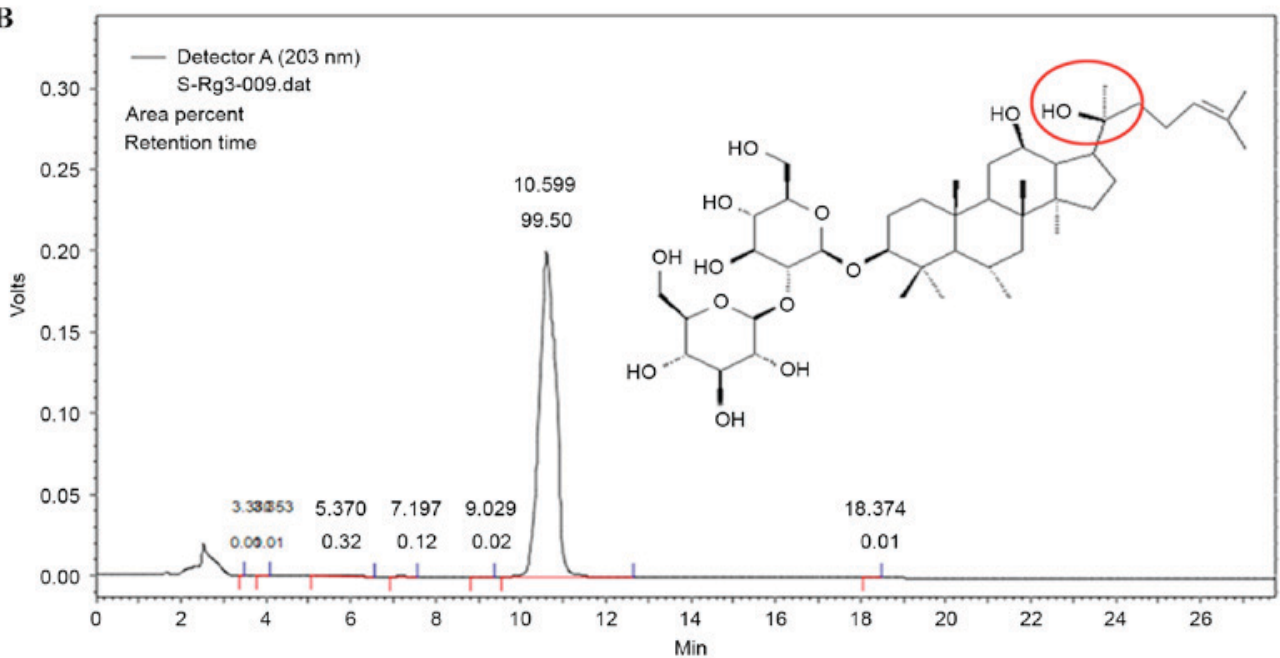

Figure 1. Chemical structure and HPLC chromatogram of 20(R)-ginsenoside Rg3 and 20(S)-ginsenoside Rg3. The X-axis shows the retention time and the Y-axis shows the voltage. The position of the asymmetric carbon atom in ginsenoside Rg3 is marked with a red circle. From the HPLC chromatograms of standards, the 20(R)-ginsenoside Rg3 retention time was $\sim 11.5 \mathrm{~min}$, compared with the 20(S)-ginsenoside Rg3 retention time of $10.5 \mathrm{~min}$. (A) R type; (B) S type. HPLC, high performance liquid chromatography. 
A

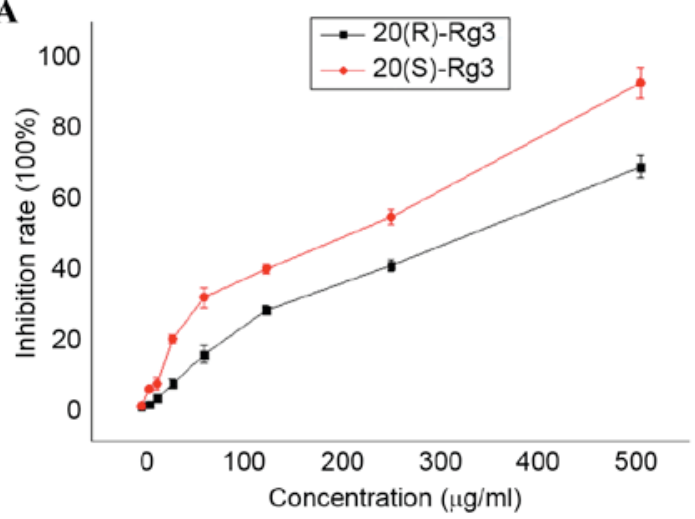

B

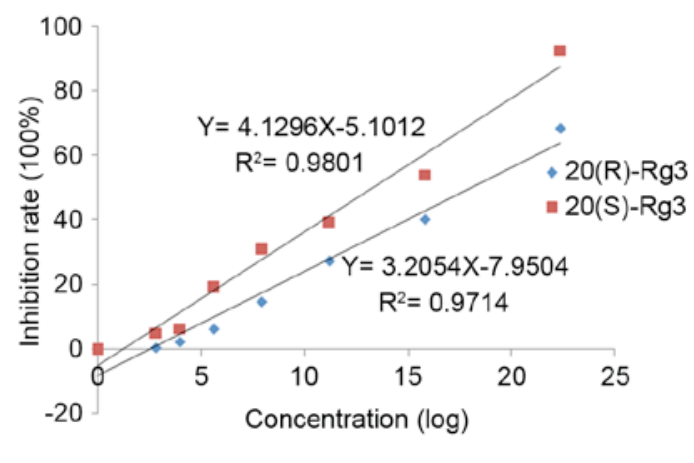

Figure 2. Inhibitory effect of ginsenoside Rg3 on HepG2 cell proliferation. (A) Growth inhibition curve for HepG2 cells treated with ginsenoside Rg3. HepG2 cells were treated with various concentrations $(0,7.81,15.63,31.25,62.5,125,250$ and $500 \mu \mathrm{g} / \mathrm{ml})$ of ginsenoside $\mathrm{Rg} 3 \mathrm{using}$ a doubling dilution every $48 \mathrm{~h}$, and cell viability was measured using a Cell Counting Kit-8 assay. (B) Linear regression equation of logarithm (base 10) concentration and inhibition ratio. The $\mathrm{X}$-axis shows the logarithm (base 10) concentration of ginsenoside Rg3, and the Y-axis shows the mean value of the inhibition ratio.

A

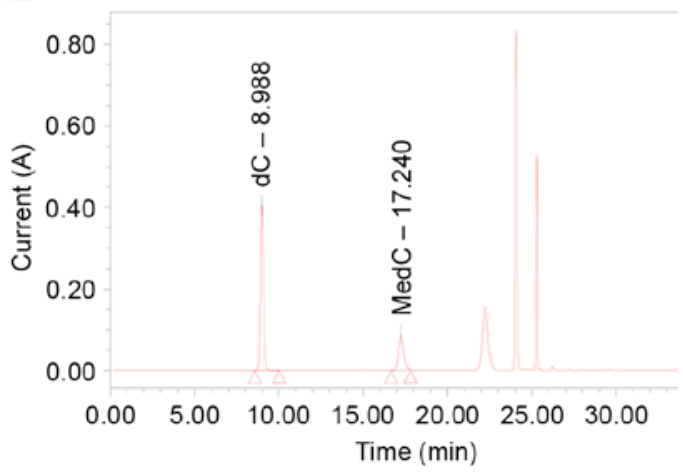

B

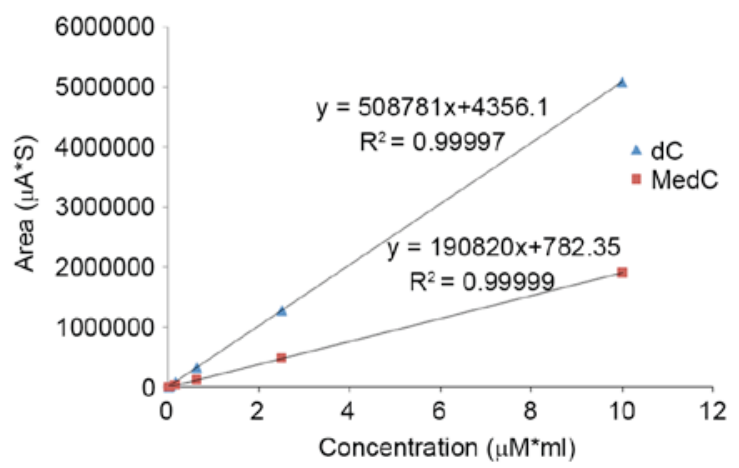

Figure 3. Chromatogram and curve for standard dC and 5-MedC. (A) Chromatogram of standard nucleotide mixture. The same concentrations of a mixture of 5-MedC, dG, dT, dC and dA were diluted into various concentrations and detected using high performance liquid chromatography. dC and MedC are marked on the chart. The $\mathrm{X}$-axis shows retention time and the $\mathrm{Y}$-axis shows the voltage. (B) Linear regression curves for the dC and MedC. The $\mathrm{X}$-axis shows the concentration of $\mathrm{dC}$ and $\mathrm{MedC}$, and the Y-axis shows the peak area value. 5-MedC, 5-methyl-2'-deoxycytidine; dC, 2'-deoxycytidine.

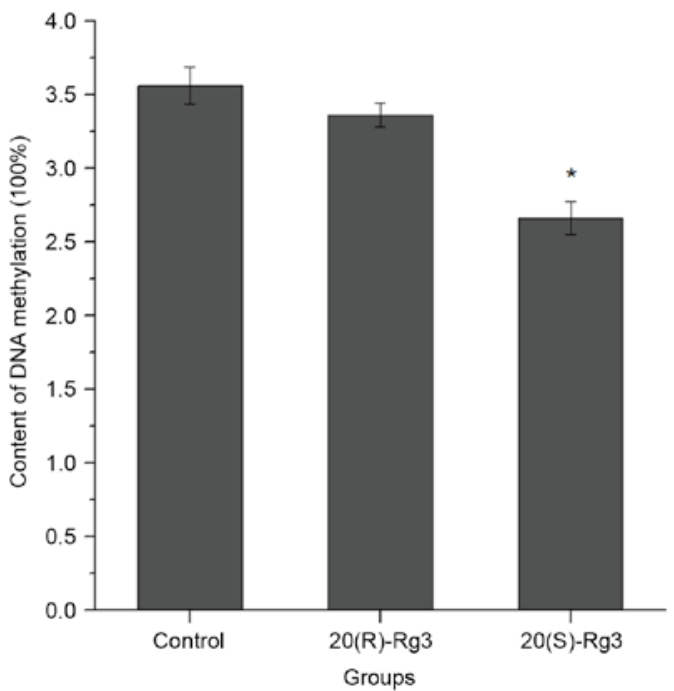

Figure 4. Alterations in DNA methylation in HepG2 cells treated with ginsenoside Rg3. HepG2 cells were left untreated, or were treated with $326.84 \mu \mathrm{g} / \mathrm{ml} 20$ (R)-ginsenoside $\mathrm{Rg} 3$ or $178.03 \mu \mathrm{g} / \mathrm{ml} 20$ (S)-ginsenoside $\mathrm{Rg} 3$, and the DNA was purified and hydrolyzed prior to detection using high performance liquid chromatography. The percentage of cytosine methylation was calculated, and the values in the treatment groups were compared with those in the untreated group. ${ }^{*} \mathrm{P}<0.05$, vs. control. by MspI. However, a weak specific band was observed in the 20(S)-ginsenoside Rg3-treated sample digested by HpaII. These data indicated that the cytosine demethylation at this site was induced by ginsenoside $\operatorname{Rg} 3$, and that 20(R)-ginsenoside $\mathrm{Rg} 3$ had a higher potential to induce methylation at this site, compared with 20(S)-ginsenoside Rg3. Alterations in DNA methylation at the CCGG sequence (1,981-1,984 bp) in the VEGF promoter are shown in Fig. 5C. No significant differences were found in the amplification profiles among the three groups, which indicated that the DNA methylation status was not altered following ginsenoside Rg3 treatment. Alterations in DNA methylation at the CCGG sequence $(5,641-5,644 \mathrm{bp})$ in the P53 promoter are shown in Fig. 5D, and an amplification band was found in the untreated control and 20(R)-ginsenoside Rg3-treated sample digested by HpaII, however, no band was observed for the 20(S)-ginsenoside Rg3-treated sample digested by HpaII. These data indicated that DNA methylation was decreased upon treatment with 20(S)-ginsenoside Rg3 at this site, whereas the DNA methylation status remained unchanged (Table II). If the band patterns remained unchanged, compared with those of the untreated control group, it was scored 0 . If the patterns showed that cytosine methylation was increased, it was scored 1 . If the patterns showed that cytosine methylation 
Table II. MspI/HpaII polymerase chain reaction assay.

\begin{tabular}{|c|c|c|c|c|}
\hline \multirow[b]{2}{*}{ Gene } & \multirow[b]{2}{*}{ Primers used } & \multirow[b]{2}{*}{ Position of CCGG site (bp) } & \multicolumn{2}{|c|}{ Methylation score } \\
\hline & & & R-Rg3 & S-Rg3 \\
\hline $\mathrm{Bcl} 2$ & $\mathrm{XZ}-82 / \mathrm{XZ}-83$ & $1701-1704 ; 1715-1718$ & 0 & 0 \\
\hline $\mathrm{Bcl} 2$ & $\mathrm{XZ}-84 / \mathrm{XZ}-85$ & 1903-1906 & 0 & 0 \\
\hline $\mathrm{Bcl} 2$ & XZ-86/XZ-87 & $1977-1980 ; 1982-1985 ; 2000-2003$ & 1 & 1 \\
\hline $\mathrm{Bcl} 2$ & XZ-88/XZ-89 & $2141-2144$ & 0 & 0 \\
\hline $\mathrm{Bcl} 2$ & XZ-90/XZ-91 & 2176-2179; 2181-2184; 2198-2199; 2225-2228 & 0 & 2 \\
\hline $\mathrm{Bcl} 2$ & XZ-94/XZ-95 & $2371-2374$ & 2 & 0 \\
\hline $\mathrm{Bcl} 2$ & XZ-96/XZ-97 & $2673-2676 ; 2689-2692$ & 0 & 0 \\
\hline $\mathrm{Bcl} 2$ & XZ-98/XZ-99 & $2844-2947$ & 0 & 0 \\
\hline $\mathrm{Bcl} 2$ & XZ-100/XZ-101 & 2946-2949 & 1 & 2 \\
\hline $\mathrm{Bcl} 2$ & XZ-102/XZ-103 & $3095-3098$ & 0 & 0 \\
\hline $\mathrm{Bcl} 2$ & XZ-104/XZ-105 & $3163-3166$ & 2 & 0 \\
\hline \multirow[t]{2}{*}{$\mathrm{Bcl} 2$ total } & & & 1: $18 \%$ & $1: 9 \%$ \\
\hline & & & $2: 18 \%$ & $2: 18 \%$ \\
\hline VEGF & XZ-106/XZ-107 & $1435-1438$ & 2 & 1 \\
\hline VEGF & XZ-110/XZ-111 & $1981-1984$ & 0 & 0 \\
\hline VEGF & $\mathrm{XZ}-112 / \mathrm{XZ}-113$ & $2120-2123$ & 1 & 0 \\
\hline VEGF & XZ-114/XZ115 & $2225-2228$ & 0 & 0 \\
\hline VEGF & XZ-116/XZ-117 & $2275-2278 ; 2285-2288 ; 2299-2302$ & 1 & 1 \\
\hline VEGF & XZ-118/XZ-119 & $2384-2385$ & 1 & 0 \\
\hline VEGF & XZ-120/XZ-121 & $2512-2515$ & 2 & 2 \\
\hline \multirow[t]{2}{*}{ VEGF total } & & & 1: $42 \%$ & 1: $29 \%$ \\
\hline & & & $2: 29 \%$ & $2: 14 \%$ \\
\hline P53 & XZ-162/XZ163 & $4928-4931$ & 0 & 1 \\
\hline P53 & XZ-164/XZ-165 & $5108-5111$ & 2 & 2 \\
\hline P53 & XZ-168/XZ-169 & $5476-5479$ & 1 & 0 \\
\hline P53 & XZ-170/XZ-171 & $5641-5644$ & 0 & 2 \\
\hline P53 & XZ-172/XZ-173 & $5675-5678$ & 2 & 0 \\
\hline P53 & XZ-174/XZ-175 & $5717-5720$ & 0 & 0 \\
\hline P53 & XZ-176-XZ-177 & $5831-5834$ & 0 & 0 \\
\hline \multirow[t]{2}{*}{ P53 total } & & & 1: $14 \%$ & 1: $14 \%$ \\
\hline & & & 2: $29 \%$ & 2: $29 \%$ \\
\hline \multirow[t]{2}{*}{ Overall total } & & & 1: $24 \%$ & 1: $16 \%$ \\
\hline & & & $2: 24 \%$ & $2: 20 \%$ \\
\hline
\end{tabular}

0, unchanged; 1, methylation; 2, demethylation; Bcl2, B cell lymphoma 2, VEGF, vascular endothelial growth factor.

was decreased, it was scored 2. The results of the MspI/HpaII PCR analysis showed that the percentages of CCGG sites remaining unchanged were 52 and $64 \%$ following treatment with 20(R)-ginsenoside Rg3 and 20(S)-ginsenoside Rg3, respectively. The percentages of methylated bands were 24 and $16 \%$ in the 20(R)-ginsenoside Rg3 and 20(S)-ginsenoside $\mathrm{Rg} 3$-treated groups, whereas the percentages of demethylated bands were 24 and $20 \%$ in the 20(R)-ginsenoside Rg3- and 20(S)-ginsenoside Rg3-treated group, respectively. From the data in Table II, it was found that the level of DNA methylation was decreased at the promoter region of P53 and BCL2 in cells treated with $20(\mathrm{~S})$-ginsenoside $\mathrm{Rg} 3$, and that the gene expression of P53 was increased, whereas that of BCL2 was decreased. The level of DNA methylation was increased in the promoter region of VEGF and decreased in that of P53 upon treatment with 20(R)-ginsenoside $\mathrm{Rg} 3$. In addition, the gene expression of VEGF was decreased, whereas that of P53 was increased. These results indicated that gene expression was not only associated with the level of DNA methylation, but was also associated with specific sites in the promoter region of the gene.

DNMT1 is upregulated, and DNMT3a and DNMT3b are downregulated by ginsenoside Rg3. The expression levels of DNMTs are closely linked to DNA methylation patterns. To investigate the molecular mechanism of cytosine methylation induced by ginsenoside Rg3, the mRNA levels of DNMT1, DNMT3a and DNAMT3b were measured using RT-qPCR 
A

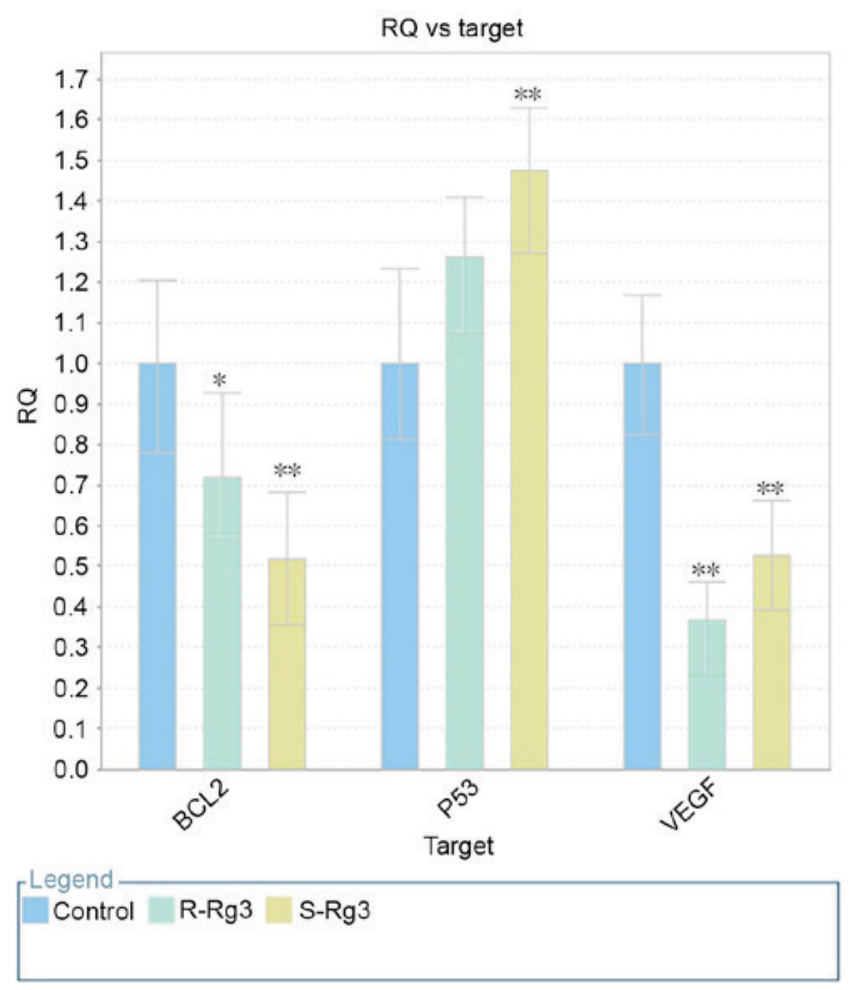

B

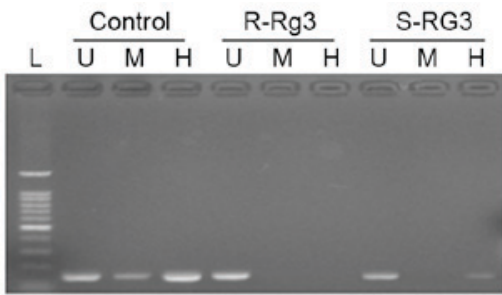

C

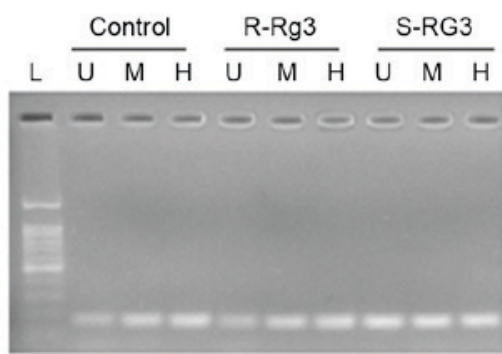

D

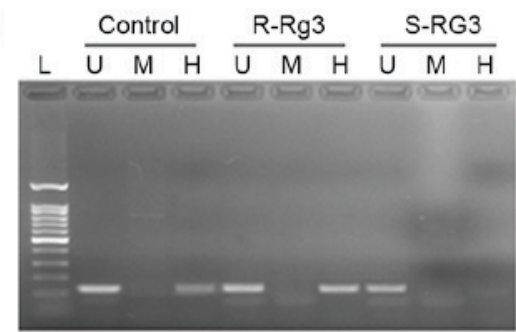

Figure 5. Effect of ginsenoside Rg3 on the gene expression and promoter region DNA methylation of P53, BCL2 and VEGF. (A) Effect of ginsenoside Rg3 on the mRNA expression of Bcl2, p53 and VEGF. The values in the treated groups were compared with those in the untreated control group ( $\mathrm{P}<0.05$ and $\left.{ }^{* *} \mathrm{P}<0.01\right)$. (B) Example of the effect of ginsenoside Rg3 on DNA methylation at the promoter region of Bcl2. (C) Example of the effect of ginsenoside Rg3 on DNA methylation at the promoter region of VEGF. (D) Example of the effect of ginsenoside Rg3 on the DNA methylation at the promoter region of P53. BCL2, B cell lymphoma 2; VEGF, vascular endothelial growth factor; L, DNA ladder; U, undigested; M, digested with MspI; H, digested with HpaII.

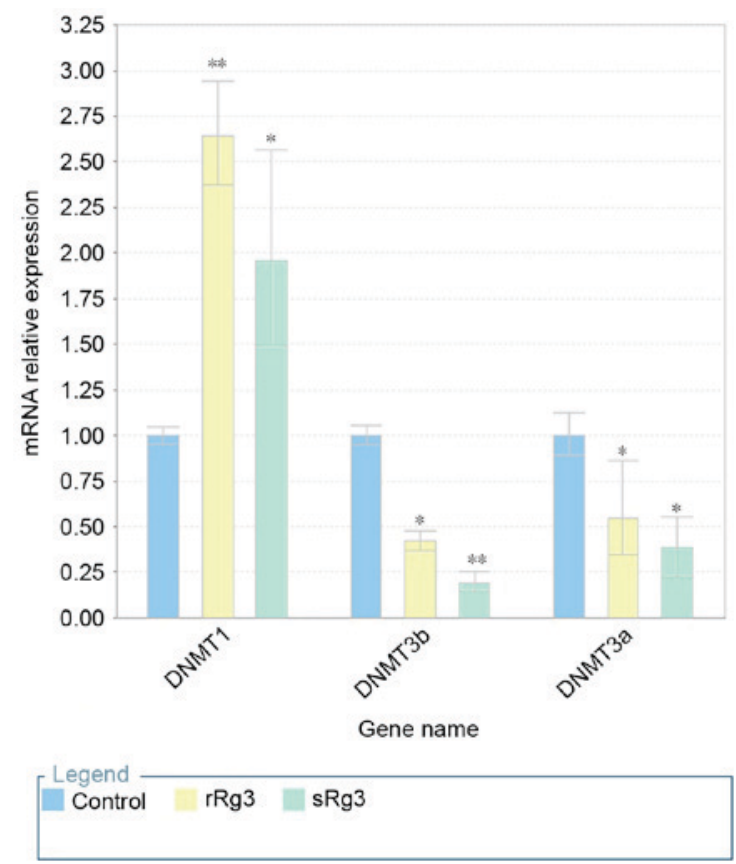

Figure 6. Effect of ginsenoside Rg3 on the expression of DNMT1 and DNMT3. ${ }^{*} \mathrm{P}<0.05$ and ${ }^{* *} \mathrm{P}<0.01$, vs. untreated control. DNMT, DNA methyltransferase.

analysis following the treatment of HepG2 cells with ginsenoside Rg3 for $24 \mathrm{~h}$. As shown in Fig. 6, the exposure of HepG2 cells to ginsenosides $\mathrm{Rg} 3$ significantly increased the mRNA expression of DNMT1, compared with that in the untreated cells $(\mathrm{P}<0.001)$. However, the mRNA expression levels of DNMT3a and DNMT3b showed significant decreases following exposure to ginsenoside $\operatorname{Rg} 3(\mathrm{P}<0.001)$, compared with the untreated cells, particularly the mRNA level of DNMT3a, which was reduced to $<0.25 \%$ of that in the untreated cells. Therefore, 20(S)-ginsenoside Rg3 treatment differentially regulated the expression of DNMT, possibly resulting in a decrease of global demethylation.

\section{Discussion}

Several reports have demonstrated that ginsenoside $\operatorname{Rg} 3$ has pharmacological actions through regulating gene expression (25). In the present study, the CCK8 data showed that the ability of $20(\mathrm{~S})$-ginsenoside Rg3 to inhibit HepG2 cell growth was more marked, compared with that of 20(R)-ginsenoside Rg3. The HPLC assay also demonstrated that 20(S)-ginsenoside $\mathrm{Rg} 3$ induced a more marked reduction in global DNA methylation, compared with 20(R)-ginsenoside $\mathrm{Rg} 3$. DNA hypomethylation has been reported in hepatocellular carcinoma and hypomethylation is associated with DNA damage, the promotion of carcinogenesis and activation of tumor suppressor genes (16). Thus, DNA hypomethylation induced by ginsenoside $\operatorname{Rg} 3$, particularly 20(S)-ginsenoside $\mathrm{Rg} 3$, may be responsible for the inhibition of HepG2 cell proliferation. 
The present study further investigated the effect of ginsenoside $\operatorname{Rg} 3$ on the methylation of the promoter regions of specific genes. In total, three genes were selected, which are closely associated with tumor angiogenesis, growth and apoptosis. P53 is important in apoptosis, genomic stability and the inhibition of angiogenesis, and its expression is increased by ginsenoside-Rg3 treatment (26). VEGF stimulates vasculogenesis and angiogenesis. The overexpression of VEGF can cause vascular disease and the development of cancer. A decrease in its expression is induced by 20-ginsenoside $\mathrm{Rg} 3$ (23). Bcl2 inhibits cell apoptosis and is classified as an oncogene. The expression was increased by 20 -ginsenoside $\mathrm{Rg} 3$ (5). Classically, hypermethylation of the promoter region is associated with gene silencing, and hypomethylation of the promoter region is correlated with gene activation. In the present study study, it was found that hypomethylation of the promoter region of P53 was consistent with gene activation. DNA methylation of the promoter regions of BCL2 were unchanged or decreased, however, the methylated sites of the promoter region and the gene expression were altered, suggesting that the DNA methylation level and the specific methylated site of the promoter region may be important for gene expression.

DNMTs are responsible for continued and de novo DNA methylation. DNMT1 maintains the DNA methylation status by maintaining the transfer of methyl groups to the newly synthesized DNA strands during DNA replication. DNMT3a and DNMT3b introduce the novel methylated cytosine site to the unmodified cytosine residues. Oh et al (27) reported that the DNA methylation and expression of DNMT1, DNMT3a and DNMT3b were higher in hepatocellular carcinoma, compared with those in normal liver tissue. In the present study, it was found that treatment with ginsenoside $\mathrm{Rg} 3$ increased the relative mRNA levels of DNMT1, but significantly reduced the levels of DNMT3a and DNMT3b. Therefore, low expression levels of DNMT3a and DNMT3b may account for decreased methylation, although high levels of DNMT1 expressed during DNA replication maintained the methylation pattern.

20(S)-Ginsenoside Rg3 and 20(R)-ginsenoside Rg3 have exhibited stereo-specific effects in several studies. For example, Kim et al (19) showed that 20(R)-ginsenoside $\mathrm{Rg} 3$ regulates the expression of multiple genes during the initiation of the transforming growth factor- $\beta 1$-induced epithelial-mesenchymal transition and suppresses lung cancer development, whereas 20(S)-ginsenoside Rg3 does not. Park et al (20) showed that 20(S)-ginsenoside Rg3 has more potent anticancer activity, compared with 20(R)-ginsenoside $\mathrm{Rg} 3$ in inducing human gastric cancer cell apoptosis. In the present study, 20(S)-ginsenoside Rg3 exhibited more potent antiproliferative effects on HepG2 cells and induced a more marked reduction in the methylation of global DNA and CpG islands, compared with 20(R)-ginsenoside Rg3, and reduced the expression levels of DNMT3a and DNMT3b. Thus, the different ginsenoside $\operatorname{Rg} 3$ epimers exhibit different stereo-specific effects in different types of cell, and selection of the appropriate epimer is required for treating different diseases.

In conclusion, data obtained in the present study indicated that ginsenoside $\mathrm{Rg} 3$ inhibited HepG2 cell proliferation in a dose-dependent manner, induced a reduction in the methylation of global genomic DNA and, for a promoter region of a specific gene, upregulated the expression of DNMT1 and downregulated the expression of DNMT3a and DNMT3b. In addition, 20(S)-ginsenoside Rg3 exhibited superior biological activity, compared with 20(S)-ginsenoside $\mathrm{Rg} 3$. These data indicated that 20(S)-ginsenoside $\mathrm{Rg} 3$ may offer increased potential, compared with 20(R)-ginsenoside $\mathrm{Rg} 3$, as an adjuvant treatment for hepatocellular carcinoma.

\section{Acknowledgements}

The authors would like to thank the National Natural Science Foundation of China (grant no. 31200953) and the China Postdoctoral Science Foundation Funded Project (grant no. 2013M530977) for financial support.

\section{References}

1. Shan X, Fu YS, Aziz F, Wang XQ, Yan Q and Liu JW: Ginsenoside $\operatorname{Rg} 3$ inhibits melanoma cell proliferation through down-regulation of histone deacetylase 3 (HDAC3) and increase of p53 acetylation. PLoS One 9: e115401, 2014.

2. Joo EJ, Chun J, Ha YW, Ko HJ, Xu MY and Kim YS: Novel roles of ginsenoside $\mathrm{Rg} 3$ in apoptosis through downregulation of epidermal growth factor receptor. Chem Biol Interact 233: 25-34, 2015.

3. Shan X, Tian LL, Zhang YM, Wang XQ, Yan Q and Liu JW: Ginsenoside Rg3 suppresses FUT4 expression through inhibiting $\mathrm{NF}-\kappa \mathrm{B} / \mathrm{p} 65$ signaling pathway to promote melanoma cell death. Int J Oncol 47: 701-709, 2015.

4. Zeng D, Wang J, Kong P, Chang C, Li J and Li J: Ginsenoside Rg3 inhibits HIF-1 $\alpha$ and VEGF expression in patient with acute leukemia via inhibiting the activation of PI3K/Akt and ERK1/2 pathways. Int J Clin Exp Pathol 7: 2172-2178, 2014.

5. Luo Y, Zhang P, Zeng HQ, Lou SF and Wang DX: Ginsenoside $\operatorname{Rg} 3$ induces apoptosis in human multiple myeloma cells via the activation of Bcl-2-associated X protein. Mol Med Rep 12: 3557-3562, 2015.

6. Ge X, Zhen F, Yang B, Yang X, Cai J, Zhang C, Zhang S, Cao Y, Ma J, Cheng H and Sun X: Ginsenoside Rg3 enhances radiosensitization of hypoxic oesophageal cancer cell lines through vascular endothelial growth factor and hypoxia inducible factor 1 $\alpha$. J Int Med Res 42: 628-640, 2014

7. Kim JH, Cho SY, Lee JH, Jeong SM, Yoon IS, Lee BH, Lee JH, Pyo MK, Lee SM, Chung JM, et al: Neuroprotective effects of ginsenoside $\operatorname{Rg} 3$ against homocysteine-induced excitotoxicity in rat hippocampus. Brain Res 1136: 190-199, 2007.

8. Yoon SJ, Park JY, Choi S, Lee JB, Jung H, Kim TD, Yoon SR, Choi I, Shim S and Park YJ: Ginsenoside Rg3 regulates S-nitrosylation of the NLRP3 inflammasome via suppression of iNOS. Biochem Biophys Res Commun 463: 1184-1189, 2015.

9. Paska AV and Hudler P: Aberrant methylation patterns in cancer: A clinical view. Biochem Med (Zagreb) 25: 161-176, 2015.

10. Poke FS, Qadi A and Holloway AF: Reversing aberrant methylation patterns in cancer. Curr Med Chem 17: 1246-1254, 2010

11. Price RJ, Lillycrop KA and Burdge GC: Folic acid supplementation in vitro induces cell type-specific changes in BRCA1 and BRCA 2 mRNA expression, but does not alter DNA methylation of their promoters or DNA repair. Nutr Res 35: 532-544, 2015.

12. Gadgil MS, Joshi KS, Naik SS, Pandit AN, Otiv SR and Patwardhan BK: Association of homocysteine with global DNA methylation in vegetarian Indian pregnant women and neonatal birth anthropometrics. J Matern Fetal Neonatal Med 27: 1749-1753, 2014.

13. Sie KK, Li J, Ly A, Sohn KJ, Croxford R and Kim YI: Effect of maternal and postweaning folic acid supplementation on global and gene-specific DNA methylation in the liver of the rat offspring. Mol Nutr Food Res 57: 677-685, 2013.

14. Sceusi EL, Loose DS and Wray CJ: Clinical implications of DNA methylation in hepatocellular carcinoma. HPB (Oxford) 13: 369-376, 2011.

15. Komatsu Y, Waku T, Iwasaki N, Ono W, Yamaguchi C and Yanagisawa J: Global analysis of DNA methylation in early-stage liver fibrosis. BMC Med Genomics 5: 5, 2012. 
16. Nishida $\mathrm{N}$ and Kudo M: Alteration of epigenetic profile in human hepatocellular carcinoma and its clinical implications. Liver Cancer 3: 417-427, 2014.

17. Livak KJ and Schmittgen TD: Analysis of relative gene expression data using real-time quantitative PCR and the 2(-Delta Delta C(T)) method. Methods 25: 402-408, 2001.

18. Wu R, Ru Q, Chen L, Ma B and Li C: Stereospecificity of ginsenoside $\mathrm{Rg} 3$ in the promotion of cellular immunity in hepatoma H22-bearing mice. J Food Sci 79: H1430-H1435, 2014.

19. Kim YJ, Choi WI, Jeon BN, Choi KC, Kim K, Kim TJ, Ham J, Jang HJ, Kang KS and Ko H: Stereospecific effects of ginsenoside 20-Rg3 inhibits TGF- $\beta 1$-induced epithelial-mesenchymal transition and suppresses lung cancer migration, invasion and anoikis resistance. Toxicology 322: 23-33, 2014.

20. Park EH, Kim YJ, Yamabe N, Park SH, Kim HK, Jang HJ, Kim JH, Cheon GJ, Ham J and Kang KS: Stereospecific anticancer effects of ginsenoside $\mathrm{Rg} 3$ epimers isolated from heat-processed American ginseng on human gastric cancer cell. J Ginseng Res 38: 22-27, 2014.

21. Cheong JH, Kim H, Hong MJ, Yang MH, Kim JW, Yoo H, Yang H, Park JH, Sung SH, Kim HP and Kim J: Stereoisomer-specific anticancer activities of ginsenoside $\mathrm{Rg} 3$ and $\mathrm{Rh} 2$ in $\mathrm{HepG} 2$ cells: Disparity in cytotoxicity and autophagy-inducing effects due to 20(S)-epimers. Biol Pharm Bull 38: 102-108, 2015.
22. Fragou D, Zanos P, Kouidou S, Njau S, Kitchen I, Bailey A and Kovatsi L: Effect of chronic heroin and cocaine administration on global DNA methylation in brain and liver. Toxicol Lett 218: 260-265, 2013.

23. Zhou B, Wang J and Yan Z: Ginsenoside Rg3 attenuates hepatoma VEGF overexpression after hepatic artery embolization in an orthotopic transplantation hepatocellular carcinoma rat model. Onco Targets Ther 7: 1945-1954, 2014.

24. Yuan HD, Quan HY, Zhang Y, Kim SH and Chung SH: 20(S)-Ginsenoside Rg3-induced apoptosis in HT-29 colon cancer cells is associated with AMPK signaling pathway. Mol Med Rep 3: 825-831, 2010.

25. Lü JM, Yao Q and Chen C: Ginseng compounds: An update on their molecular mechanisms and medical applications. Curr Vasc Pharmacol 7: 293-302, 2009.

26. Zhang F, Li M, Wu X, Hu Y, Cao Y, Wang X, Xiang S, Li H, Jiang L, Tan Z, et al: 20(S)-ginsenoside Rg3 promotes senescence and apoptosis in gallbladder cancer cells via the p53 pathway. Drug Des Devel Ther 9: 3969-3987, 2015.

27. Oh BK, Kim H, Park HJ, Shim YH, Choi J, Park C and Park YN: DNA methyltransferase expression and DNA methylation in human hepatocellular carcinoma and their clinicopathological correlation. Int J Mol Med 20: 65-73, 2007. 